\title{
Què cal saber per ensenyar matemàtiques a l'educació primària: resultats d'una recerca
}

\author{
Celia Giné de Lera \\ Universitat Autònoma de Barcelona \\ mariacelia.gine@uab.cat
}

Resum: La recerca didàctica estableix que per ensenyar una matèria es requereixen coneixements fonamentats, tant sobre la disciplina a què es refereix la matèria com sobre la seva didàctica. En el cas de les matemàtiques, les dades d'un estudi internacional actual (TEDS-M) han posat de manifest deficiències relatives als programes sobre la formació inicial en matemàtiques i la seva didàctica dels futurs mestres a Espanya. Aquest article contrasta aquests resultats a partir d'una recerca amb mestres $i$ estudiants de mestre de primària, identifica les dificultats que tenen els estudiants de mestre en relació amb alguns coneixements necessaris per a l'ensenyament de les matemàtiques entorn de la resolució de problemes $i$ analitza quines d'aquestes dificultats es redueixen i quines romanen amb l'experiència docent.

Paraules clau: Educació matemàtica, resolució de problemes, coneixements del professor, formació del professorat, educació primària.

Abstract: Educational research establishes that sound knowledge is required in order to teach a subject, both knowledge of the own discipline and of their didactics. In the case of mathematics, data from an international study (TEDS-M) has shown current deficiencies relating to future teachers training programs in mathematics and its teaching in Spain. This article contrasts these results from a research with in-service and pre-service primary teachers, by identifying the difficulties of pre-service teachers regarding some knowledge for teaching mathematics around problem solving, and analyzing which of these difficulties are reduced or which remain with the teaching experience.

Keywords: Mathematics education, problem solving, teacher knowledge, teacher education, primary education.

\section{Introducció}

Segons Pólya (1962), la principal finalitat de les matemàtiques escolars és ensenyar els alumnes a pensar. "Ensenyar a pensar" vol dir que un mestre de matemàtiques no ha d'impartir únicament informació, sinó que ha d'intentar també desenvolupar l'habilitat dels alumnes per utilitzar la informació subministrada: ha d'emfatitzar coneixements, actituds útils i hàbits mentals desitjables. Aquest "pensar" l'identifiquem, almenys en una primera aproximació, amb la resolució de problemes. Però tenen els mestres de matemàtiques els recursos i coneixements necessaris per ensenyar matemàtiques entorn de la resolució de problemes?

Un mestre de matemàtiques adquireix els coneixements professionals en la seva escolarització, en la formació universitària inicial i en l'experiència docent ( $i$, en alguns casos, en la formació permanent). Tot i això, és important saber els coneixements que tenen els estudiants en el moment que se'ls capacita per accedir a la professió docent, sobretot quan ens referim al 
coneixement de la matèria, que s'hauria d'haver adquirit essencialment abans d'exercir de docent. Posteriorment, l'experiència dota els docents de nous coneixements: resulta interessant per al disseny de la formació del professorat saber quins són aquests coneixements i reflexionar sobre si alguns d'ells es podrien haver adquirit anteriorment.

El treball que presentem forma part d'un estudi més ampli en el qual es caracteritzen i comparen els coneixements i les creences sobre la resolució de problemes de professors i estudiants de professor d'educació primària i secundària (Giné, 2012). En concret, en aquest article ens proposem caracteritzar i comparar els coneixements sobre resolució de problemes d'estudiants de mestre de primària i de mestres de primària, per identificar així, d'una banda, les dificultats que puguin tenir els estudiants de mestre en relació amb alguns coneixements necessaris per a l'ensenyament de les matemàtiques $i$, de l'altra, quines d'aquestes dificultats varien, o fins i tot arriben a desaparèixer, amb l'experiència docent.

\section{Referents teòrics}

Encara que la resolució de problemes juga un paper prominent en els esforços de reforma de l'educació matemàtica (NCTM, 2000), molts docents se senten mal preparats a l'hora d'ensenyar a resoldre problemes, $i$ han tingut poca experiència a resoldre, ells mateixos, problemes que requereixin més que simples aplicacions d'algorismes i fórmules (Epperson, 2004). Per ensenyar matemàtiques entorn de la resolució de problemes un mestre ha de tenir una bona base de coneixements conceptuals i procedimentals (Hiebert i Carpenter, 1992), ja que el seu desconeixement pot ser una barrera per resoldre molts problemes. No obstant això, aquests coneixements no són suficients: tot professor ha de tenir un coneixement que va "més enllà" del coneixement del contingut en si mateix (Shulman, 1986), que és el que alguns especialistes han anomenat mathematical knowledge for teaching (MKT) (Ball, Thames i Phelps, 2008). Aquest coneixement general l'han dotat de dues dimensions: el mathematics content knowledge (MCK) i el mathematics pedagogical content knowledge (MPCK); el primer és el coneixement del contingut de la disciplina en si mateixa i el segon, la relació que hi ha entre saber un coneixement per un mateix $i$ ser capaç de fer que altres l'entenguin.

Alguns estudis ja han utilitzat el marc de l'MKT per analitzar la formació inicial de mestres a escala global, com el TEDS-M 2008 (Tatto et alii, 2008, 2012), els resultats del qual mostren que les puntuacions mitjanes obtingudes pels futurs mestres espanyols en les proves sobre coneixements estan per sota de la mitjana internacional, tant en coneixements matemàtics (MCK) com de didàctica de la matemàtica (MPCK). Aquests resultats han posat de manifest deficiències relatives als programes sobre la formació en matemàtiques i la seva didàctica dels futurs mestres, i han destacat la necessitat d'una profunda reforma dels plans d'estudi de magisteri.

\section{Metodologia}

La nostra recerca utilitza una metodologia mixta, quantitativa-qualitativa, amb l'objectiu d'obtenir una visió general dels resultats $i$, a la vegada, poder fer una mirada específica sobre algunes dades que ens semblen rellevants.

Per a l'obtenció de les dades s'ha elaborat un protocol de problemes que s'ha passat a dues mostres heterogènies respecte a l'experiència docent: la primera, formada per 16 estudiants de mestre de primària $i$, la segona, per 10 mestres de primària en actiu.

La mostra dels estudiants de mestre es va prendre en el curs 2011-2012, en un grup classe de la Universitat Autònoma de Barcelona del $3 r$ curs d'Educació Primària (curs en el qual ja han cursat totes les assignatures troncals de matemàtiques i de la seva didàctica). Les mostres de mestres han estat preses d'una forma més heterogènia, $i$ hi ha mestres de diferents centres de Catalunya, que han accedit a omplir el protocol de forma voluntària al llarg del curs 2011-2012.

Per elaborar el protocol de problemes, ens hem basat en la classificació dels tipus de coneixement matemàtic per a l'ensenyament emprada en l'estudi TEDS-M 2008 per crear, a partir d'ella, una classificació pròpia adaptada als objectius específics del nostre treball, que mostrem a continuació: 


\begin{tabular}{|c|c|c|c|c|}
\hline \multicolumn{2}{|c|}{$M C K$} & \multicolumn{3}{|c|}{ MPCK } \\
\hline Conèixer & Raonar & Curricular & Planificació & Transformació \\
\hline Recordar & Analitzar & \multirow{4}{*}{$\begin{array}{l}\text { Conèixer els } \\
\text { continguts del } \\
\text { currículum }\end{array}$} & \multirow[b]{2}{*}{$\begin{array}{l}\text { Planificar problemes } \\
\text { adequats al contingut }\end{array}$} & \multirow[b]{2}{*}{$\begin{array}{l}\text { Explicar/representar } \\
\text { diferents enfocaments/ } \\
\text { procediments }\end{array}$} \\
\hline \multirow[t]{3}{*}{$\begin{array}{c}\text { Reconèixer } \\
\text { objectes } \\
\text { matemàtics en un } \\
\text { context diferent }\end{array}$} & $\begin{array}{c}\text { Integrar diferents } \\
\text { elements del } \\
\text { coneixement } \\
\text { matemàtic }\end{array}$ & & & \\
\hline & Generalitzar & & \multirow{2}{*}{$\begin{array}{c}\text { Adaptar problemes per } \\
\text { variar-ne la dificultat }\end{array}$} & \multirow{2}{*}{$\begin{array}{c}\text { Analitzar/avaluar } \\
\text { solucions dels alumnes }\end{array}$} \\
\hline & Justificar & & & \\
\hline
\end{tabular}

En els ítems relatius a l'MCK, hem utilitzat ítems d’opció múltiple (resposta tancada) i, en els relatius a l'MPCK, hem utilitzat ítems de resposta oberta (però guiada), ja que el coneixement pedagògic és més subjectiu i complex. En l'apartat d'anàlisi mostrarem alguns dels ítems del protocol de problemes.

\section{Anàlisi de dades i resultats}

Hem comparat els nivells de coneixements de les dues mostres en els cinc dominis de les dimen- sions de l'MKT definides anteriorment. S'ha associat cada domini de coneixement a un nombre del rang $[-3,3]$ segons el valor de la mitjana del conjunt dels individus que constitueixen la mostra, considerant un nivell baix $[-3,-1)$, mitjà $[-1,1)$ o alt $(1,3]$.

Als gràfics 1 i 2, hi mostrem les mitjanes del nivell de coneixements de cada mostra en els dominis i subdominis de l'MKT.

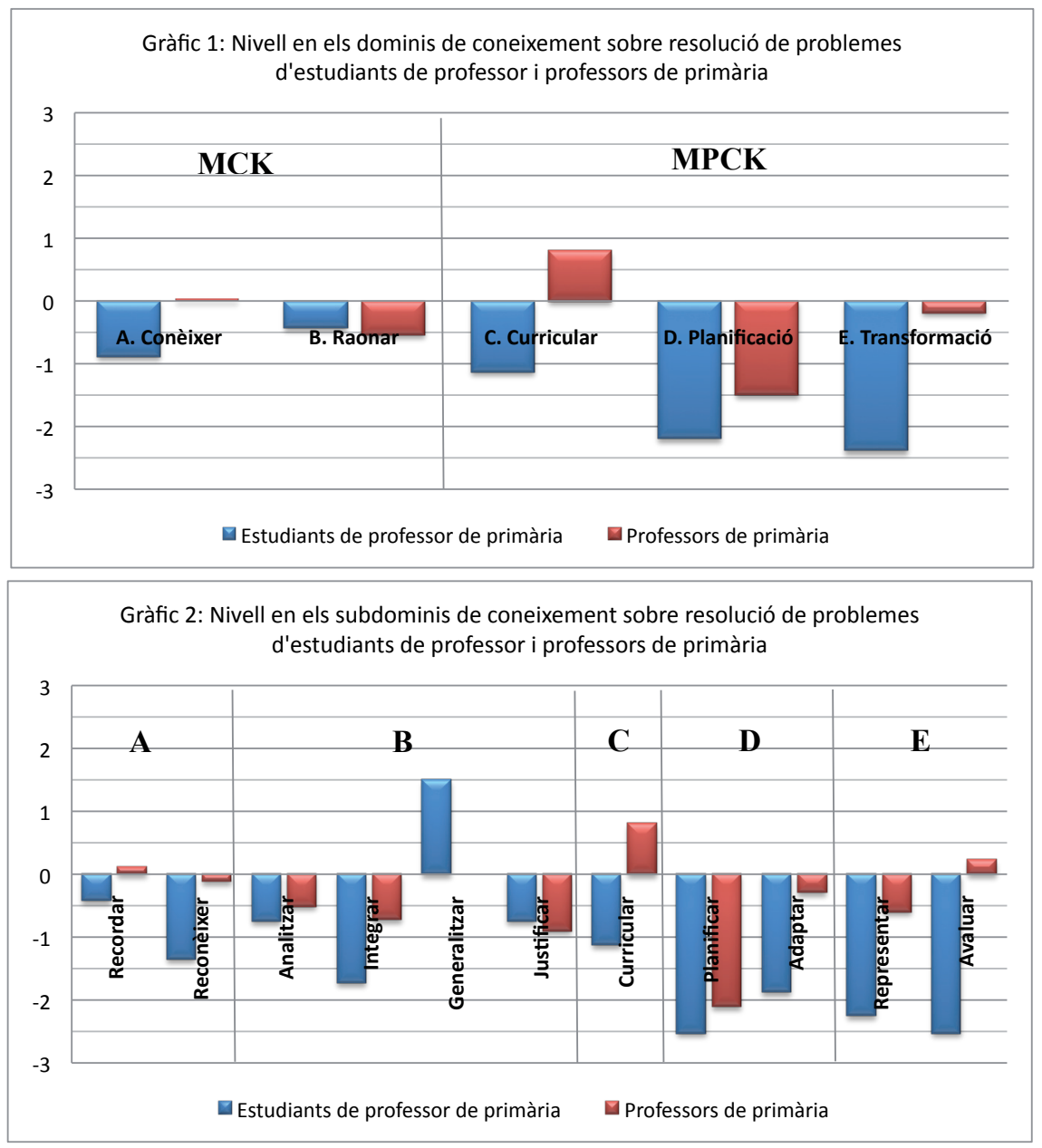


Aquesta organització de les dades ens dóna una visió general de les dues mostres i ens permet visualitzar diferències significatives en el nivell d'alguns dominis de coneixement, en general superior en els mestres.

A continuació, mostrem una part de l'anàlisi qualitativa, tot donant exemples de respostes dels mestres i estudiants de mestre de primària per ítems del protocol relatius a cada domini de coneixement.

\section{A. Conèixer}

L’Elisabet dibuixa a la pissarra la recta numèrica següent, i situa les fraccions $1 / 3$ i $1 / 5$ de la manera següent:

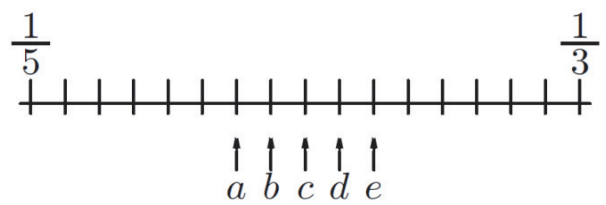

Demana als alumnes que situïn la fracció $1 / 4$, i cinc alumnes surten a la pissarra a fer la seva solució. La Marta situa $1 / 4$ al punt $a$, en Joaquim al $b$, la Raquel al $c$, la Sara al $d$ i l'Eugeni a l'e. Qui ha situat 1/4 correctament?

Per resoldre aquest problema es necessita conèixer diversos aspectes al voltant del concepte de fracció (encara que això no és suficient, ja que caldrà també raonar). Concretament, cal:

- Recordar: Propietats de les fraccions. Representació de fraccions en la recta numèrica.

- Reconèixer: Interpretar el gràfic donat com una porció de recta numèrica que no comença per 0 .

La dificultat del problema rau especialment a reconèixer, ja que alumnes i mestres estan acostumats a situar nombres racionals en la recta numèrica però habitualment partint del 0 .

La resposta correcta és la a, i es poden utilitzar diferents resolucions per arribar a la solució. És possible que el problema sigui difícil, però tot $\mathrm{i}$ així, algú que coneix la interpretació de fraccions sobre la recta real, i en particular les fraccions unitàries, hauria de poder arribar a la conclusió que $1 / 4$ és més proper a $1 / 5$ que a $1 / 3$, i amb això descartar les opcions c, d, e (l'opció c — punt mitjà entre $1 / 5$ i $1 / 3-$, correspon a $4 / 15$, que és superior a 1/4).

Els resultats obtinguts en la resolució aquest problema són:

- Estudiants de mestre de primària: a: 1, b:2, c: 12 , d: 0 , e: 0 , no responen (NR): 2 . Només 1 alumne ha estat capaç de donar la resposta correcta, mentre que 12 dels altres 16 creuen que $1 / 4$ es troba exactament al mig d'1/3 i 1/5. Aquest és un error conceptual significatiu, on la confusió té, molt possiblement, l'arrel en el fet que 4 es troba exactament en el punt mitjà entre 3 i 5 .

- Mestres de primària: a: $5, \mathrm{~b}: 0, \mathrm{c}: 2, \mathrm{~d}: 0$, e: 0, NR: 3. En aquest cas, la meitat dels mestres han trobat la solució, però encara hi ha l'altra meitat que o no saben la resposta o pensen també que $1 / 4$ és el punt mitjà entre $1 / 3$ i $1 / 5$. No obstant això, la resposta incorrecta $c$, donada per la majoria dels estudiants (12 de 16), es redueix a 2 (de 10). 


\section{B. Raonar}

En una llista de problemes del teu curs, et trobes el problema següent:

Imagina que tens 108 boles vermelles i 180 de verdes. Les vols repartir, totes, en sacs (sense que en sobri ni en falti cap) de manera que en tots els sacs hi hagi el mateix nombre de boles, i que totes les boles de cada sac siguin del mateix color. Quin és el mínim nombre de sacs que necessites?

Quina és la resposta correcta?

a) 288 ; b) 36 ; c) 18 ; d) 8 ; e) 1 .

Per resoldre el problema cal:

- Analitzar: Determinar la relació entre les dades del problema i el que ens demanen.

- Integrar: Combinar diferents procediments matemàtics per establir el resultat (per exemple, màxim comú divisor i divisió, encara que altres resolucions són possibles).

En aquest cas, l'anàlisi del problema resulta clau: el resolutor ha d'adonar-se que el que ens demana el problema no és el nombre de boles que hi haurà a cada sac (que es troba fent el màxim comú divisor de 108 i 180 i dóna 36), sinó el nombre de sacs necessaris $(108+180=288$ boles, si posem 36 boles en cada sac calen 288 : $36=8$ sacs). Per tant, si aquesta anàlisi no es produeix correctament, és d'esperar que l'error més freqüent sigui triar la resposta b. Vegem les respostes de les dues mostres:

- Estudiants de mestre de primària: $a: 0, b: 6$, c: 3 , d: 6 , e: $0, \mathrm{NR}: 1$. Hi ha tants alumnes que han trobat la resposta correcta del problema com alumnes que han comès l'error descrit anteriorment (37,8\% en cada cas), mentre que 3 alumnes han triat la resposta $\mathrm{c}$ i un no ha respost.

- Mestres de primària: a: $0, \mathrm{~b}: 5, \mathrm{c}: 1, \mathrm{~d}: 4$, e: 0 , NR: 0 . En aquest cas, la meitat dels mestres han comès l'error previst (b), més dels que han encertat la resposta (d). Tot i això, observem, d'una banda, que la proporció d'individus que han obtingut la resposta correcta és major en els mestres que en els estudiants ( $40 \% / 37,8 \%$ ), i de l'altra, que els estudiants han comès diferents tipus d'errors, alguns amb arrel incerta, mentre que els mestres s'han equivocat gairebé tots en el mateix (l'error "esperat").

\section{Coneixement curricular}

[Relacionat amb el problema anterior] Quins dels següents continguts del curs són necessaris per resoldre el problema? (Marca tots els que creguis necessaris)?

a) Probabilitat; $b$ ) mínim comú múltiple; $c$ ) màxim comú divisor; $d$ ) divisió d’enters.

Hem de fer notar que per resoldre el problema inicial és útil el càlcul del màxim comú divisor, però no és imprescindible conèixer que aquest procediment es diu així ni cal saber calcular-lo de forma mecànica. Per tant, podria ser que algú, tot i fer bé el problema (b), marqués una opció errònia en aquest ítem (c), on el que avaluem és que coneixen el concepte de màxim comú divisor.

Hem considerat que el més correcte és assenyalar les respostes $\mathrm{c}$ i d, mentre que només marcar la c es considera parcialment correcte i qualsevol altra opció es considera incorrecta. Notem també que un mateix individu pot marcar més d'una resposta; per tant, la suma de les respostes analitzades no donarà el total d'individus de la mostra.

Vegem les respostes:

- Estudiants de mestre de primària: $\mathrm{a}: 5, \mathrm{~b}$ : 3, c: 6, d: 9. A banda de la confusió que hi pugui haver entre mínim comú múltiple i màxim comú divisor, l'error més greu és pensar que el problema és de probabilitat (l'han marcat 5 dels 16 estudiants), fet motivat pel context del problema (treure boles de sacs). La resposta correcta l'han marcat menys de la meitat dels estudiants (6 de 16).

- Mestres de primària: a: $0, b: 2, c: 9, \mathrm{~d}: 3$. Tots menys un mestre de primària han considerat que es necessitava el màxim comú divisor per resoldre el problema, amb la qual cosa veiem clarament que el seu coneixement curricular és significativament més gran que el dels estudiants de 
mestre de primària. Ningú no ha pensat que es tractava d'un problema de probabilitat, i només dos mestres han considerat que es necessitava el mínim comú múltiple (dels quals un també ha marcat el màxim comú divisor).

\section{Coneixements sobre planificació}

La Sandra i en Martí han anat a buscar bolets. N'han trobat 70 (només rovellons i ceps). 5/9 parts dels bolets trobats per la Sandra eren rovellons, mentre que $2 / 17$ parts dels trobats pel Martí eren ceps. Quants bolets ha trobat la Sandra?

Crea un problema diferent però del mateix tipus (mateixos processos o operacions) que sigui més fàcil de resoldre per als teus alumnes.

El problema es pot resoldre mitjançant un estudi de casos, en el qual hem de tenir en compte que el nombre de bolets de la Sandra és múltiple de $9 \mathrm{i}$ el nombre de bolets de Martí de 17, i que la suma total és 70. Usant el mateix raonament, també es pot resoldre mitjançant l'equació diofàntica $9 \mathrm{x}+$ $17 \mathrm{y}=70$, on 9x són els bolets de la Sandra i $17 \mathrm{y}$ els del Martí. En ambdós casos, la solució és que la Sandra ha trobat 36 bolets i en Martí 34.

Quant a la redacció d'un problema del mateix tipus, 10 estudiants de mestre (dels 16) han intentat crear un problema, dels quals només 1 ho ha fet correctament, mentre que 7 dels 10 mestres de primària han creat un problema, 2 dels quals de forma correcta. Atès el baix percentatge d'encerts, quina ha estat la dificultat que han tingut les dues mostres per crear un problema més fàcil?

La principal raó per la qual no saben redactar un problema més fàcil és que no han sabut analitzar i resoldre correctament el problema inicial: en tots els casos han cregut que es tractava d'un problema "de fraccions" en lloc d'un problema "de divisibilitat". Per tant, en crear el nou problema, transformen l'original en un problema de fraccions, fet que canvia totalment la naturalesa del problema (i, per tant, els processos i operacions necessaris per resoldre'l). En aquests casos (més de la meitat dels individus de cada mostra), passa que el fet de no saber resoldre correctament el problema i no identificar el tipus de problema i els conceptes involucrats els porta a no saber proposar-ne un de més senzill per als seus alumnes, és a dir, que la manca de coneixement matemàtic els comporta un problema didàctic.

\section{E. Coneixements sobre transformació}

En un llistat de problemes sobre percentatges, la Mercè es troba els problemes següents:

1. En una botiga de música dos $\mathrm{CD}$ tenien el mateix preu, però un l'han rebaixat un $5 \%$, mentre que l'altre l'han apujat un $15 \%$. Després d'aquestes variacions, la diferència de preu entre els dos és de $6 €$. Quin és el preu que tenien els $\mathrm{CD}$ al principi?

2. Durant una carrera sobserva que, després d'un cert nombre de voltes, els corredors han recorregut el $20 \%$ del total de la distància prevista, i que, després d'una altra volta, ja hauran recorregut el $25 \%$. Quantes voltes s'han de donar a la pista per acabar la carrera?

3. L'Àlex, l'Helena i la Sofia han recollit diners per poder comprar-se una tenda de campanya. La Sofia aporta el $60 \%$ del preu total. La quantitat que té l'Àlex representa el $40 \%$ de la resta. D'aquesta manera, a l'Helena li queden per pagar $30 €$. Quant costa la tenda?

4. Una persona té un pati rectangular al seu jardí. Decideix fer-lo més gran augmentant tant la seva longitud com l'amplada en un $10 \%$. Quin serà el percentatge d'increment de l'àrea del pati?

Relaciona cadascuna de les resolucions següents amb els problemes anteriors $(1,2,3$, 4) i indica si és una resolució correcta.

a) Si les dimensions lineals augmenten un $10 \%$, làrea també.

b) Solució = 100: $(25-20)$

c) $1-(0,6+0,24)=0,16 ;$ solució $=(30 \times$ 100): 16

d) Solució $=(6 \times 100):(15+5)$ 
Els resultats són il.lustratius del nivell de coneixements de cada mostra: cap dels 16 estudiants de mestre de primària no ha sabut avaluar correctament totes les resolucions d'aquests problemes; només 1 estudiant ha sabut avaluar 2 de les solucions de forma correcta; els altres estudiants, cap. A la mostra de mestres, els resultats són clarament diferents: 6 dels 10 han avaluat correctament els quatre problemes, 3 n'han encertat algun, i només un mestre ha deixat la pregunta en blanc.

\section{Conclusions}

És una creença generalitzada que la formació matemàtica dels mestres de primària és insuficient. Això és avalat per recerques recents com el TEDS-M: l'informe assenyala insuficiències i deficiències en els plans de formació del professorat d'educació primària, i conclou que "els nous plans d'estudi de formació de mestres hauran d'introduir importants canvis en la titulació, en l'estructura dels plans de formació i en els programes per aprofundir en la formació de mestres de matemàtiques de primària" (Instituto Nacional de Evaluación Educativa, 2012: 128). En el nostre estudi hem constatat que, tant pel que $\mathrm{fa}$ al coneixement matemàtic com al de la seva didàctica, es presenten una sèrie de dificultats $i$ errors que al nostre entendre són rellevants per poder ensenyar matemàtiques d'una manera satisfactòria a l'educació primària.

Els nostres resultats mostren que els estudiants de mestre de primària tenen dificultats significatives tant en relació amb els coneixements matemàtics (MCK) com de didàctica de la matemàtica (MPCK). Pel que fa als coneixements matemàtics, destaquen les seves mancances en reconèixer objectes matemàtics en contextos on no estan habituats a utilitzar-los, i també quan es tracta d'integrar i establir connexions entre diferents elements del coneixement matemàtic. Quant als coneixements de didàctica de la matemàtica, el nivell és baix en tots els dominis analitzats: coneixement curricular, de planificació i de transformació.

Moltes de les mancances detectades en els estudiants de mestre milloren o desapareixen en els professors de primària. És el cas dels conei- xements matemàtics: els mestres no presenten grans dificultats en cap subdomini de conèixer $o$ raonar, encara que els seus coneixements no són alts. De la mateixa manera, en la majoria de coneixements sobre la didàctica de la matemàtica no hi tenen dificultats (respecte als estudiants, el nivell millora especialment en coneixement curricular i en la capacitat per avaluar les solucions dels alumnes), excepte en planificar problemes adequats al contingut matemàtic que es vol ensenyar, tasca en la qual també presenten dificultats significatives.

Així mateix, el nostre estudi ha posat de manifest mancances, tant en els mestres com en els estudiants, en alguns dominis del coneixement didàctic, especialment en planificar o transformar problemes per a fins pedagògics concrets. Respecte d'això, hem obtingut alguns resultats concrets però rellevants sobre algunes de les raons que poden obstaculitzar l'ensenyament al voltant de la resolució de problemes. Una d'aquestes dificultats ha estat la incapacitat (sobretot dels estudiants de professor) per identificar els continguts matemàtics necessaris per resoldre un problema a partir del context de l'enunciat, fet que posa de manifest el pes dels "problemes tipus" per a cada contingut matemàtic, i que dificulta, al seu torn, tant la capacitat de proposar problemes amb contextos variats com la de transformar un problema en un altre del mateix tipus però variant-ne la dificultat. Per tant, les nostres dades posen de manifest que, en molts casos, la manca de coneixement matemàtic impossibilita el tractament didàctic dels problemes de matemàtiques.

Finalment, entenem que els resultats de la nostra recerca mostren deficiències en el coneixement matemàtic per a l'ensenyament tant dels mestres com, sobretot, dels estudiants de mestre, fet que preocupa gestors, experts, professors i investigadors a Espanya (Instituto Nacional de Evaluación Educativa, 2012), i que posa de manifest la necessitat de fer, en la formació inicial, un major èmfasi tant en el coneixement sobre didàctica de la matemàtica com, especialment, en el coneixement del contingut matemàtic per a l'ensenyament, ja que, com hem pogut constatar, la falta d'aquest coneixement comporta també deficiències en el coneixement didàctic. 


\section{Referències bibliogràfiques}

Ball, D. L.; Thames, M. H.; Phelps, G. (2008). "Content knowlegde for teaching. What makes it special?" Journal of Teacher Education, 59 (5), 389-407.

Epperson, J. (2004). "Strengthening inservice secondary mathematics teachers' understanding and strategies in mathematical problem solving". Paper presented at the annual meeting of the North American Chapter of the International Group for the Psychology of Mathematics Education, Delta Chelsea Hotel. Toronto, Ontario (Canadà).

GINÉ, C. (2012). Coneixements i creences sobre la resolució de problemes de professors i estudiants de professor d'educació primària i secundària: un estudi sobre la continuïtat en l'ensenyament de les matemàtiques. Tesi doctoral. Universitat Autònoma de Barcelona.

Hiebert, J.; Carpenter, T. (1992). "Learning and teaching with understanding", a: D. Grouws. Handbook for research on mathematics teaching and learning. Nova York: MacMillan, p. 65-97.

Instituto Nacional de Evaluación EducaTIVA (2012). TEDS-M. Informe español. Estu- dio internacional sobre la formación inicial en matemáticas de los maestros. Madrid: Ministerio de Educación, Cultura y Deporte.

National Council of Teachers of Mathematics (NTCM). (2000). Principles and standards for school mathematics. Reston, VA: l'autor.

Pólya, G. (1962). Mathematical discovery. Nova York: John Wiley and Sons.

Shulman, L. (1986). “Those who understand, knowledge growth in teaching". Educational Researcher, 15 (2), 4-14.

TAтто, M. T., et alii (2008). Teacher Education and Development Study in Mathematics (TEDS-M): conceptual framework. East Lansing, MI: Teacher Education and Development International Study Center, College of Education, Michigan State University.

Tatтo, M. T., et alii (2012). Policy, practice and readiness to teach primary and secondary mathematics in 17 countries. Findings from the IEA TeacherEducation and Development Study in Mathematics (TEDS-M). Christchurch, Nova Zelanda: Paula Wagemaker Editorial Services. 